\title{
Characteristics of Blockchain Technology In Educational Development
}

\author{
Rano Kurniawan ${ }^{1}$, Duwita Oktaviani \\ University of Raharja, Indonesia ${ }^{1,2}$ \\ Jl. Jenderal Sudirman No.40, RT.002/RW.006, Cikokol, Kec. Tangerang, Kota Tangerang, \\ Banten $15117^{1,2}$ \\ e-mail: Rano@raharja.info', duwita@raharia.info²
}

Kurniawan, R., Oktaviani, D., Characteristics of Blockchain Technology In Educational Development.

Blockchain Frontier Technology (B-Front), 1(1), 82-93.

DOI : https://journal.pandawan.id/b-front/article/view/41

\begin{abstract}
The worldwide education implementation process has not been able to keep up with contemporary events. The education sector is now dealing with a number of issues, including the problem of verification and the presence of a third party in the management of certificates, which are micro and macro outputs of a company's learning process. The existence of a beacon of Blockchain technology, which is frequently referred to as a revolutionary solution to the current educational debate. In the education business, the merger of education with blockchain technology will usher in a new era. There are numerous reasons for this solution, but I don't believe they are sufficient to describe the features of blockchain in detail from the perspective of education utilizing blockchain, which examines the presence of blockchain for education based on scientific investigations. These features of blockchain will be highly valuable as a literary platform for scholars who will begin fundamental research and applications that will lead to blockchain for education in the future. Aside from that, there will be recommended solutions in the form of a framework for the cost, storage space, and speed of blockchain technology. As a result, this research can also serve as a basis for the new blockchain as a predecessor of technology-based governance blockchains.
\end{abstract}

Keywords: Blockchain, Education, Development

\section{Introduction}

Education has revolutionized the nation's government and is excellent [1]. However, if the process of spreading education internationally is investigated further, it cannot be stated to be ideal in the current state of the industrial revolution 4.0 [2]. The problems in the field of education are numerous, ranging from tamper-proof verification processes to the inclusion of a third party in every process of implementing the system in the education ecosystem [3]. Then, in an age strongly associated with this technology, comes a breakthrough technology and the word Blockchain. As a foundation for this study, an agile approach was used, which has a significant influence on every company sector now in operation [4]. The combination of Blockchain with the area of education may be described as a wonderful partnership that is highly relevant for current educators, leading to the coining of the phrase "blockchain characteristics." This study will serve as a foundation for rookie researchers who are going to embark on a research project. Blockchain technology is also subjected to basic study. Agile methodologies have been recognized as one of the most useful instruments in motivating each work and also minimizing time so that it is more useful. 
This is particularly important in the implementation of agile methodologies in the field of education so that it can maintain its consistency in developing superior human resources [5].

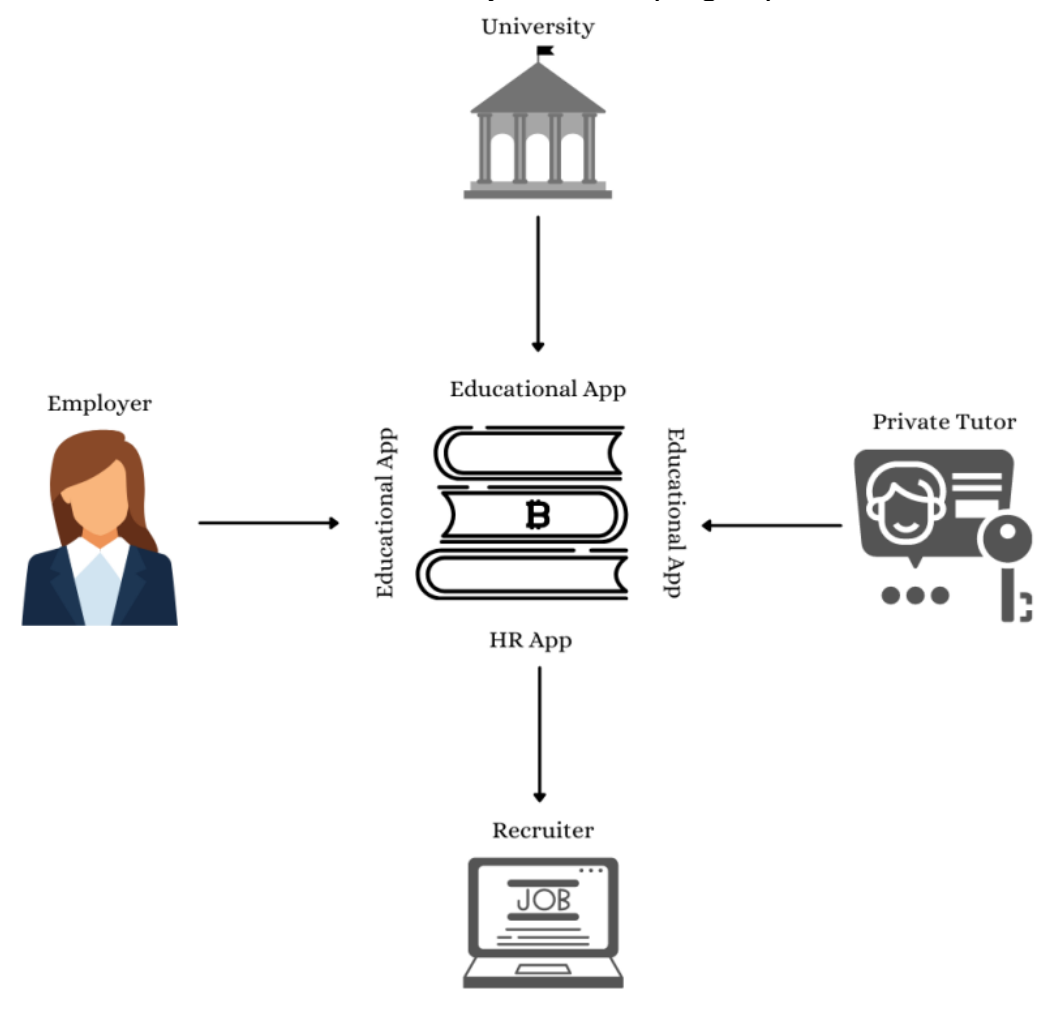

Figure 1. Educational Blockhain

Figure 1 shows how blockchain technology is being used in scope education. Essentially, blockchain technology may be used to balance and improve the work system of all devices in educational institutions [6]. Students, teachers, agency staff, and even the accreditation department are all involved. The main purpose of using blockchain in the education ecosystem is to guarantee data privacy and uniqueness [7]. And, if the system is committed to blockchain technology, there is no need for a third party to benefit from the resources that educational institutions require. The following is the research's structure: Section 2 gives an overview of blockchain for educational purposes so that flaws may be identified. The approach of the agile manifesto is explained in Section 3. Section 4 is a fundamental and in-depth explanation of the properties of blockchain in order to have a better understanding of educational management systems. Part 5 concludes this work with research findings and recommendations for further research [8].

\section{Research Method}

There are a variety of research methodologies that may be utilized in the subject of education [9], however recent advances have led to the adoption of a cutting-edge technology that is thought to assist alleviate difficulties in the field of education as follows: 


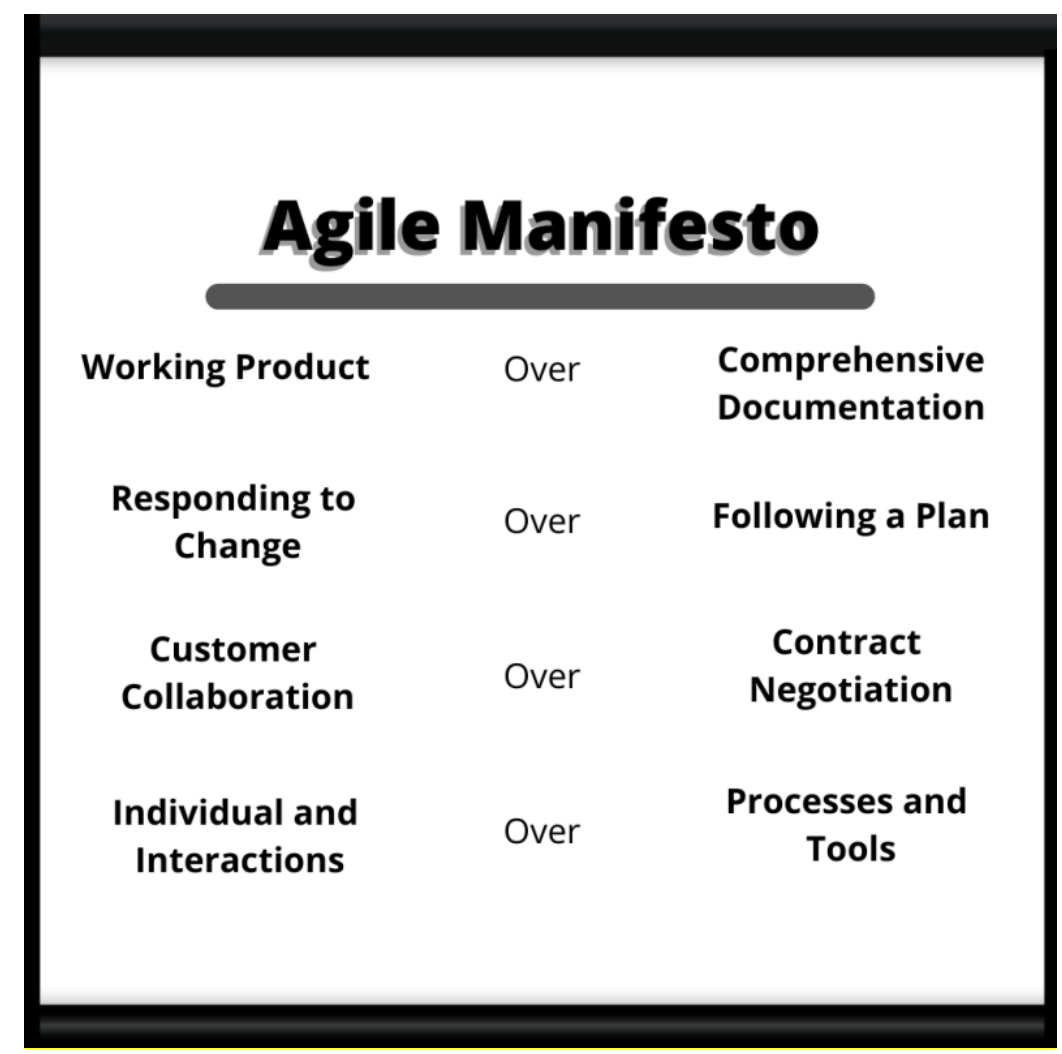

Figure 2. Agile manifesto

This study will employ the Agile Manifesto [10], as depicted in Figure 2, as a starting point for thinking about historical technology that is currently fast evolving so that new technologies may replace it. Agile began as a tool for software engineers, but it is now being employed in the field of education due to increased cooperation [11].

- Students capacity to work in an unpredictable world must be respected by individuals and interactions as instructors. As a result, students' requirements must be provided in a flexible manner without the need for severe regulations to be enforced.

- A working product that does not need you to rely just on documentation because every job must always run. Many things can be accomplished if this system is applied correctly and successfully. Also, double-check if the finished product is operational.

- Customer collaboration is required in communication in order for all sides to be more transparent, including the capacity to properly listen and provide positive feedback. In general, it may be a learning experience that yields greater outcomes than an individual can obtain elsewhere.

- Adapting to change is crucial since every system is different. In this period of industrial change, current learning does not necessarily have to follow the existing strategy. All sectors, including education, must be able to be more flexible and follow the flow of its growth in order for it to go in the proper path and become more creative. So, after understanding how The Agile Manifesto works, you can be certain that the blockchainbased education industry will be able to adapt the system and progress toward a better future.

\section{Result}

The idea of blockchain characteristics is used in this research. Clearly, despite their complicated environment, blockchain transactions share logical notions and elements that are critical to the world of education as it is now practiced. 


\subsection{Characteristics of the Blockchain}

Using hash algorithms, blockchain is known to be able to deliver digital signature services without relying on the private key and public key [12]. Education may be more effectively integrated using the capabilities of a distributed blockchain. The properties of blockchain will be examined in this study, which will include the following 5 points:

\subsection{Disintermediation vs Intermediation}

We will concentrate on the significance of disintermediation over intermediation in this paper. Intermediation is responsible for much of the current expansion in global education; one example that can be given is how intermediation has led to unsustainable practices in recent decades [13]. Because each intermediary layer must be managed, this is the case. Disintermediation, when used in the context of blockchain-based education, may decentralize the system while maintaining a consistent user perspective. Because the user has the capacity to make choices, disintermediation tends to hinder differentiation class [14]. This has the effect of deconstructing the hierarchy and empowering each component in a system. The authors then come to the conclusion that disintermediation over intermediation can permanently retain a system's fundamental operation as a technique for reducing society's complexity, expense, and throughput of materials [15].

\subsection{Decentralization over Centralization}

This consolidation [16] enables a more focused use of the "work first" and "work for all" approaches. The development of a centralized education system to support learning systems does not necessarily negate the necessity for public blockchain to be decentralized. As a result of the difficulties in acquiring an overview of the content and quality of the numerous educational platforms accessible, centralization is often the result of poor activation performance locally as an educational platform [17]. Decentralization can lead to significant disparities in rights, educational service availability, and educational service quality, as well as greater fragmentation and ambiguity, which may need lengthy discussions between the parties concerned. It is certain that decentralization over centralization may operate effectively since it lowers the accumulation of labor in educational service centers, improves efficiency in all ways, and reduces bureaucracy.

\subsection{Trustless}

There is what is known as trustless technology in the development of technology, yet a university that functions in the education sector operates on trust [18]. Instead of subjecting student confidence and learning status to verification computational methods, universities must recognize student confidence and learning status as adequate. Creating confidence in a learning system by providing safe, common, and lasting evidence. Customized blockchain applications have the ability to tackle the challenging challenge of sharing student data at educational institutions in a flexible and robust manner by considering data sharing as a series of transactions. In the education industry, blockchain establishes a trust structure. Also, make sure the box can't be erased and the data inside it is immutable.

\subsection{Immutability takes precedence over mutability}

The term "blockchain immutability" or "irreversibility" refers to the fact that transaction data in the education sector has been tampered with, and the data's history cannot be removed or changed [19]. Using the immutable mobile notion, it will be demonstrated that whereas digital mapping of interfaces in university learning systems plainly cannot change, mobile has been undergoing a subtle but significant alteration where eternity is concerned. In this approach, blockchain, which has an immutability property, can best transform formerly mutable data in the education industry. 


\subsection{CRUD}

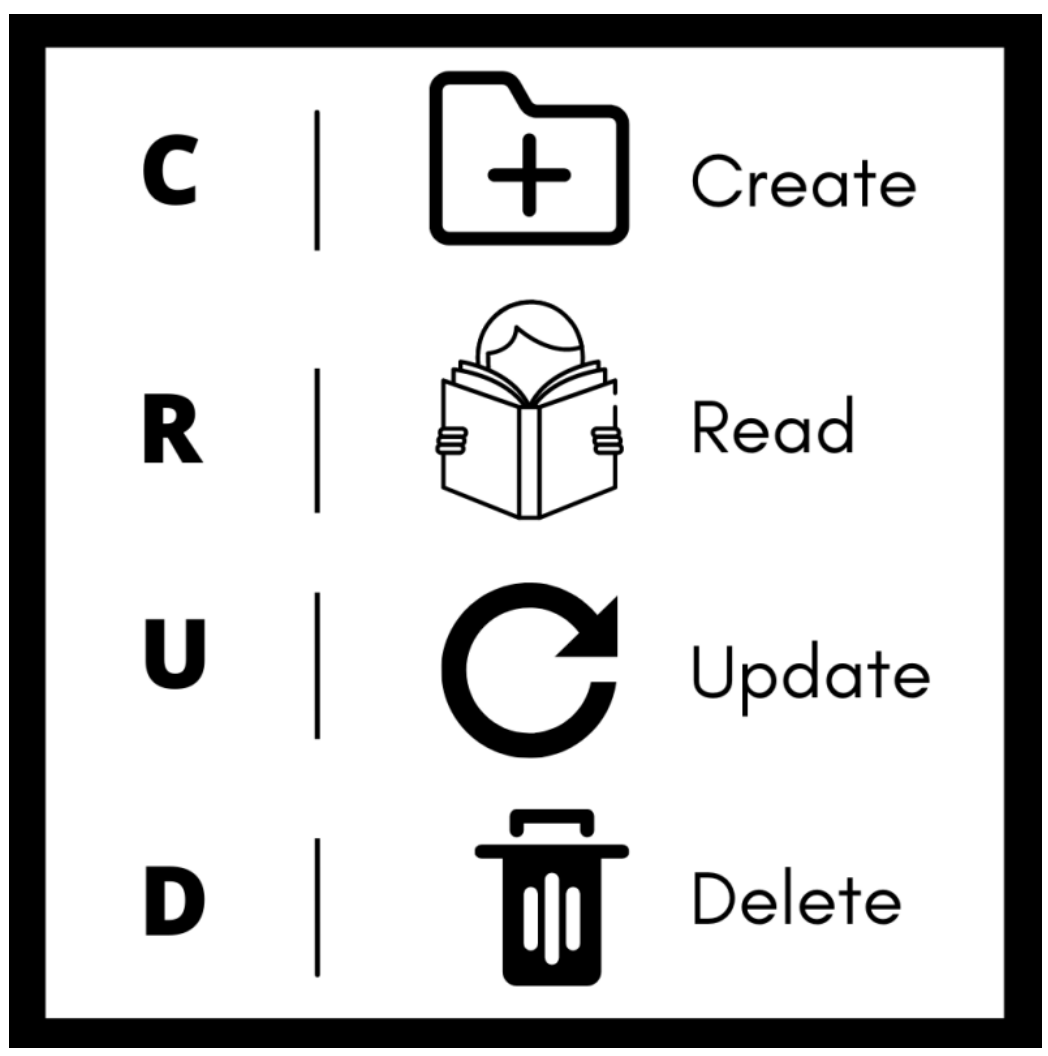

Figure 3. CRUD

Figure 3: Time performance testing for all CRUD methods in a database comparison. (1) Create: Student information is entered into the database one record at a time.

(2) Read: Because it is a distributed Master-Slave arrangement, this action is done on a single instance only.

(3) Update: This action inserts new data into the document content field of the comments collection. All papers are scanned to get a unique identification prior to updating, however this procedure is not considered for evaluating the performance time.

(4) Remove the item. This action clears the database of all data.

\section{Conclusion}

This study examines the use of blockchain in education and the blockchain approach. As a result, it may be utilized to assist educational development, implying that the properties of blockchain be applied at the educational level. With forethought, it is feasible to create automated blockchain implementations utilizing an established modeling technique. Because the technique employs the characteristics of the blockchain framework, it can optimize the world of education in the context of this research. It can provide better assistance for learning activities and monitoring in the education administration sector. As a result, this research leads to blockchain for education that uses agile methodologies to verify the presence of more valuable blockchain features. Blockchain for Education is a preliminary study that will be used to further examine blockchain technology. It utilises the properties of the present blockchain. Instead, the next critical step is to comprehend and define the connection between the blockchain's properties in order to solve additional educational challenges. It is envisaged that the blockchain's properties would aid in a more thorough examination of all implementation options.. 


\section{References}

[1] G. Sachs, "Blockchain-The new technology of trust," Retrieved April, vol. 11, p. 2018, 2018.

[2] P. Edastama, S. Purnama, R. Widayanti, L. Meria, and D. Rivelino, "The Potential Blockchain Technology in Higher Education Learning Innovations in Era 4.0," Blockchain Frontier Technology, vol. 1, no. 01, pp. 104-113, 2021.

[3] P. de Filippi and S. Hassan, "Blockchain technology as a regulatory technology: From code is law to law is code," arXiv preprint arXiv:1801.02507, 2018.

[4] H. Nusantoro, R. Supriati, N. Azizah, N. P. L. Santoso, and S. Maulana, "Blockchain Based Authentication for Identity Management," in 2021 9th International Conference on Cyber and IT Service Management (CITSM), 2021, pp. 1-8.

[5] I. K. Gunawan, N. Lutfiani, Q. Aini, F. M. Suryaman, and A. Sunarya, "Smart Contract Innovation and Blockchain-Based Tokenization in Higher Education," Journal of Education Technology, vol. 5, no. 4, pp. 636-644, 2021.

[6] D. Ahmad, N. Lutfiani, A. D. A. R. Ahmad, U. Rahardja, and Q. Aini, "Blockchain Technology Immutability Framework Design in E-Government," Jurnal Administrasi Publik: Public Administration Journal, vol. 11, no. 1, pp. 32-41, 2021.

[7] D. Yaga, P. Mell, N. Roby, and K. Scarfone, "Blockchain technology overview," arXiv preprint arXiv:1906.11078, 2019.

[8] M. Nofer, P. Gomber, O. Hinz, and D. Schiereck, "Blockchain,” Business \& Information Systems Engineering, vol. 59, no. 3, pp. 183-187, 2017.

[9] J. Schmitz and G. Leoni, "Accounting and Auditing at the Time of Blockchain Technology: A Research Agenda," Australian Accounting Review, vol. 29, no. 2, pp. 331-342, 2019, doi: 10.1111/auar.12286.

[10] P. Tasatanattakool and C. Techapanupreeda, "Blockchain: Challenges and applications," in 2018 International Conference on Information Networking (ICOIN), 2018, pp. 473-475.

[11] T. Hariguna, Y. Durachman, M. Yusup, and S. Millah, "Blockchain Technology Transformation in Advancing Future Change," Blockchain Frontier Technology, vol. 1, no. 01, pp. 13-20, 2021.

[12] P. Treleaven, R. G. Brown, and D. Yang, "Blockchain technology in finance," Computer, vol. 50, no. 9, pp. 14-17, 2017.

[13] T. Ayuninggati, E. P. Harahap, and R. Junior, "Supply Chain Management, Certificate Management at the Transportation Layer Security in Charge of Security," Blockchain Frontier Technology, vol. 1, no. 01, pp. 1-12, 2021.

[14] U. Rahardja, Q. Aini, and S. Maulana, "Blockchain innovation: Current and future viewpoints for the travel industry," IAIC Transactions on Sustainable Digital Innovation (ITSDI), vol. 3, no. 1, pp. 8-17, 2021.

[15] C. Holotescu, "Understanding Blockchain Technology and How to Get Involved," The 14th International Scientific Conference eLearning and Software for Education, no. April, pp. 1-9, 2018, doi: 10.13140/RG.2.2.25185.33126/1.

[16] H. Nusantoro, P. A. Sunarya, N. P. L. Santoso, and S. Maulana, "Generation Smart Education Learning Process of Blockchain-Based in Universities," Blockchain Frontier Technology, vol. 1, no. 01, pp. 21-34, 2021.

[17] H. D. Zubaydi, Y.-W. Chong, K. Ko, S. M. Hanshi, and S. Karuppayah, "A review on the role of blockchain technology in the healthcare domain,” Electronics, vol. 8, no. 6, p. 679, 2019.

[18] O. Ali, M. Ally, Clutterbuck, and Y. Dwivedi, "The state of play of blockchain technology in the financial services sector: A systematic literature review," International Journal of Information Management, vol. 54, no. May, p. 102199, 2020, doi: 10.1016/j.ijinfomgt.2020.102199.

[19] Y. Zhang, S. Kasahara, Y. Shen, X. Jiang, and J. Wan, "Smart contract-based access control for the internet of things," IEEE Internet Things J., vol. 6, no. 2, pp. 1594-1605, 2018.

[20] G. D. Putra, S. Sumaryono, and W. Widyawan, "Rancang Bangun Identity and Access Management IoT Berbasis KSI dan Permissioned Blockchain," J. Nas. Tek. Elektro dan Teknol. Inf., vol. 7, no. 4, pp. 384-390, 2018, doi: 10.22146/jnteti.v7i4.455.

[21] L. Thomas, Y. Zhou, C. Long, J. Wu, and N. Jenkins, "A general form of smart contract for decentralized energy systems management," Nat. Energy, vol. 4, no. 2, pp. 140-149, 2019. 